\title{
Dinâmica inflacionária da indústria brasileira: uma abordagem setorial (1999-2014)+
}

\author{
Dynamics of the Brazilian industrial inflation: \\ a sectoral approach (1999-2014)
}

FLÁVIA CARVALHO DE MORAES E SILVA*

CARMEM FEIJO $* *$

ANDRE DE MELO MODENESI***

\begin{abstract}
RESUMO: O objetivo deste trabalho é investigar o comportamento da dinâmica inflacionária industrial brasileira no período 1999 a 2014 à luz das teorias de inflação de custos e da heterogeneidade setorial. Através da teoria de formação de preços pós-Keynesiana e da teoria do conflito distributivo sobre o processo inflacionário, o trabalho aponta para a importância das diferenças na estrutura de custos setoriais para a análise sobre a inflação. Estas diferenças são importantes uma vez que podem levar a reações heterogêneas ante as diferentes pressões inflacionárias. $\mathrm{O}$ trabalho busca preencher esta lacuna e integrar as abordagens microeconômica e macroeconômica, de modo a contribuir para o diagnóstico da inflação industrial. Realiza-se um estudo econométrico com dados em painel para estimar os efeitos do impacto de variações nos custos, nos salários, na demanda e nos preços defasados sobre as variações dos preços finais. Encontramos que, levando-se em conta a heterogeneidade setorial, os choques de custos são a principal variável explicativa para a dinâmica inflacionária.
\end{abstract}

PALAVRAS-CHAVE: Inflação; heterogeneidade setorial; dados em painel; Brasil.

ABSTRACT: This paper investigates the dynamics of the Brazilian industrial inflation during 1999-2014. Based on the post-Keynesian theory on price formation and distributive conflict, the paper discusses the importance of sectoral differences for the analysis of Brazilian inflation in the 2000s. These differences are important since they can lead to heterogeneous

\footnotetext{
+ Os autores agradecem os comentários do parecerista anônimo, que muito contribuíram para o aperfeiçoamento do trabalho. Eventuais falhas que ainda persistam são de responsabilidade dos autores.

* Mestre pela Universidade Federal Fluminense, Rio de Janeiro/RJ, Brasil. Email: flaviamoraes_3@ hotmail.com.

** Professora titular da Universidade Federal Fluminense, Rio de Janeiro/RJ, Brasil e pesquisadora do CNPq. E-mail: cbfeijo@gmail.com.

*** Professor associado do Instituto de Economia da Universidade Federal do Rio de Janeiro - IE/UFRJ, Rio de Janeiro/RJ, Brasil e pesquisador do CNPq. E-mail: amodenesi@gmail.com. Submetido: 6/ Julho/2017; Aprovado: 15/Março/2018.
} 
reactions in the face of different inflationary pressures. Micro and macroeconomic approaches are considered in order to contribute to the diagnosis of Brazilian industrial inflation. An econometric exercise with panel data is conducted to estimate the effects of the impact of changes in costs, wages, demand and lagged prices on changes in final prices. We find that, considering sectoral heterogeneity, cost shocks are the main explanatory variable for the inflation dynamics.

KEYWORDS: Inflation; sectoral heterogeneity; panel data; Brazil.

JEL Classification: E12; E31; E52; E64

\section{INTRODUÇÃO}

Desde 1999 o Brasil adota o Regime de Metas de Inflação (RMI). Segundo a sistemática deste regime, uma aceleração inflacionária (em relação à meta estipulada) deve ser contraposta por uma elevação da taxa básica de juros pelo banco central, o que arrefece, por meio de diferentes canais, a demanda agregada e, consequentemente, o processo inflacionário - consideradas as defasagens da política monetária.

Quanto a esta sistemática, é importante notar duas particularidades. Primeiro, o mecanismo utilizado pelo RMI no caso de uma aceleração inflacionária - o aumento da taxa básica de juros - tem como foco mitigar um único tipo de choque inflacionário, qual seja, o choque de demanda. Isto advém do fato de que os modelos que embasam o RMI consideram que choques de custos são temporários (Clarida et al., 1999). Neste cenário, caso ocorra um choque de custo, a autoridade monetária deveria atuar apenas sobre seus efeitos secundários, através do gerenciamento da demanda agregada, sem atuar diretamente em sua causa.

Segundo, a discussão sobre os mecanismos de transmissão da política monetária assume, implicitamente, que a economia opera em um ambiente de competição perfeita. Com isso, variações na demanda agregada levarão os preços a se alterarem proporcionalmente. Contudo, tanto a teoria microeconômica neoclássica, quanto a heterodoxa, consideram que em estruturas produtivas diferentes da concorrência perfeita a competição entre empresas pode se dar via quantidades e não via preços. Neste caso o RMI não funcionaria adequadamente, apresentando um resultado diferente do previsto. Em outras palavras, aspectos microeconômicos estariam fazendo a política monetária atuar adversamente a como a teoria prevê ou, pelo menos, de uma forma heterogênea em um mesmo sistema econômico (Montani Martins et al., 2017).

As duas particularidades destacadas têm sido complementadas com importantes críticas, que confrontam abertamente os postulados por trás do RMI - e, consequentemente, sua consistência como regime monetário.

Em uma primeira frente, diferentes abordagens teóricas criticam a visão de que a dinâmica inflacionária estaria ligada essencialmente às pressões de deman- 
da. A teoria de formação de preços pós-keynesiana ${ }^{1}$ postula que, uma vez que os preços são determinados de forma estratégica pelas firmas segundo uma regra de mark-up sobre os custos, variações na demanda não influenciam os preços. Estas últimas determinam o nível de produção da firma. Trabalhos empíricos analisando a dinâmica inflacionária para a economia brasileira no período recente encontram a predominância dos custos como determinantes da inflação (Braga, 2011; Jorge, 2012; Summa, 2014; Summa e Macrini, 2014; Bastos et al., 2014). A teoria do Conflito Distributivo ${ }^{2}$ dá ênfase às pressões de custo - salários, câmbio, custos intermediários e mark-up - que explicariam em grande parte os processos inflacionários (Bastos, 2010; Lavoie, 2014: 542-3). As pressões advindas destes fatores desencadeariam um conflito pela distribuição da renda num determinado período, principalmente entre trabalhadores e capitalistas, que levaria a um processo inflacionário. A demanda teria apenas papel secundário no processo inflacionário, neste caso.

Numa segunda frente, destaca-se a influência da heterogeneidade setorial quanto ao poder de determinação dos preços das firmas sobre a dinâmica inflacionária. Esta crítica aponta que características setoriais impactam a forma como as pressões de demanda e de custo influenciam os preços e a inflação. Jorge (2012), ao analisar a dinâmica inflacionária setorialmente de 1996 a 2011 no Brasil, encontra predominância da inflação importada, medida pela taxa de câmbio e pelo índice de commodities, em todos os setores de atividade, enquanto a inflação dita de demanda foi significativa apenas em 2 dos 17 setores analisados.

O objetivo deste artigo é investigar o comportamento da dinâmica inflacionária industrial brasileira no período de 1999 a 2014 à luz das teorias de inflação de custos e da heterogeneidade setorial. Os trabalhos sobre inflação no Brasil, em geral, centram-se na análise agregada sem considerar a heterogeneidade setorial presente na economia brasileira. Estas diferenças são importantes uma vez que podem levar a reações heterogêneas ante as diferentes pressões inflacionárias. $\mathrm{O}$ objetivo aqui definido busca preencher esta lacuna e integrar as abordagens microeconômica e macroeconômica, de modo a contribuir para o diagnóstico da inflação industrial.

De modo específico, o trabalho apresenta uma análise empírico-quantitativa sobre os determinantes da inflação industrial brasileira no período mencionado, levando em consideração 21 setores industriais. Os modelos econométricos têm como metodologia dados em painel, estimados através do Método dos Momentos Generalizados (GMM) e Mínimo Quadrado Ordinário (MQO) com efeito fixo.

\footnotetext{
${ }^{1}$ Ver por exemplo, Eichner (1976); Lee (1999); Lavoie (2014).

${ }^{2} \mathrm{Na}$ tradição de Keynes, Kalecki, Sraffa, Sylos-Labini, dentre outros, a inflação é o resultado do conflito distributivo para repartição da renda gerada na economia em determinado período. Como se assume que o poder de barganha dos agentes econômicos é diferenciado, a teoria heterodoxa da inflação atribui especial atenção ao processo de determinação de preços pelas firmas para explicar variações no nível agregado de preços.
} 
Esses métodos permitem uma análise agregada levando-se em consideração a heterogeneidade setorial presente na economia, fornecendo, assim, uma perspectiva analítica da inflação nos anos 2000 micro-macro integrada.

\section{DA FORMAÇÃO DE PREÇOS AO PROCESSO INFLACIONÁRIO}

\section{A Teoria de Preços Pós-Keynesiana}

A teoria de formação de preços pós-keynesiana tem sido desenvolvida por diversos autores que apresentam semelhanças e algumas diferenças entre eles. No geral, os autores compartilham a ideia de que a determinação dos preços segue uma visão estratégica de sobrevivência e crescimento da firma nos vários mercados onde atua. ${ }^{3}$ Assumem também que os preços numa economia de mercado são administrados, e, portanto, a estrutura de mercado - se monopolista, oligopolista ou competitivo - não será determinante no processo de formação de preços.

Lavoie (2014), dentre outros, aponta que os preços determinados pelas firmas são baseados em alguma medida de custos de forma que permita a sua reprodução ao longo do tempo. $\mathrm{Na}$ avaliação do autor eles serão estáveis, com baixa elasticidade preço da demanda e não são preços market clearing. Além disso, eles são interdependentes entre si e estratégicos.

Os preços são determinados a partir de uma base de custos com a adição de um mark-up. ${ }^{4} \mathrm{O}$ mark-up terá como função garantir uma margem de lucro para as firmas e será determinado de forma que gere uma taxa de retorno desejável sobre o valor do capital investido na produção.

A literatura pós-keynesiana descreve o processo de precificação de várias formas. A principal divergência entre os autores se dá sobre como definir os custos que serão levados em consideração no momento em que a decisão de precificar estiver sendo tomada.

Segundo Lee (1999) os custos mais relevantes são: a) o custo direto médio normal, ou seja, considera os custos ligados diretamente ao processo produtivo (basicamente salários e insumos) e b) o custo total médio normal, que inclui todos os custos. Estes custos são calculados a partir de um nível de utilização de capacidade considerado como normal, que é determinado historicamente em cada setor, e portanto não depende da quantidade produzida corrente. Neste pressuposto, o preço não deve ser volátil e o lucro deve ser previsível.

Sobre esses custos é aplicado um mark-up. Autores pós-keynesianos, como Eichner (1976) e Lee (1999) entendem que o nível do mark-up de cada setor será

\footnotetext{
${ }^{3}$ A teoria da firma elaborada por Penrose (1980), por exemplo, pode ser tomada como uma teoria pós-keynesiana da firma. Ver Feijó (1993).

${ }^{4}$ A percepção de que preços são determinados por uma regra de mark-up aplicada sobre uma estrutura de custos tem sua origem no estudo seminal de Hall e Hitch (1939).
} 
determinado historicamente, ou seja, será ligado aos costumes, tradições, convenções, razoabilidade e competições de curto e longo prazo vigentes no setor em questão. Já a variação do mark-up está ligada à competição existente em cada setor e à necessidade de geração de lucro para cumprir seu objetivo final de sobreviver e crescer.

A conclusão é que os preços não se alteram com a variação na demanda, esta irá afetar o nível de produção. Os preços estarão ligados com os custos, porém o repasse das mudanças nos custos para os preços não é automática e depende da variação do mark-up que segue a visão estratégica da firma quanto ao seu potencial de crescimento. Nesta perspectiva, a determinação do mark-up não depende de um processo de otimização de lucro, pois em um contexto de incerteza não probabilística este tratamento não é possível.

\section{O Conflito Distributivo}

A teoria do conflito distributivo permite entender como o processo de precificação decidido em cada empresa resulta em pressão inflacionária no agregado. $\mathrm{O}$ objetivo aqui, então, será realizar a passagem analítica do prisma da formação de preços no nível das firmas para a concretização de um processo inflacionário em nível macroeconômico.

Os diversos modelos presentes na teoria do conflito distributivo compartilham a visão que a inflação é um fenômeno relacionado aos conflitos sobre a distribuição de renda e que a dinâmica dos custos desempenha papel fundamental na explicação da inflação (Lavoie, 2014: 542-3). O conflito acerca da distribuição da renda ocorre por diversas razões. Lavoie (2014: 545-8) aponta duas motivações principais: (i) a demanda por maior equidade ou justiça na distribuição de renda entre trabalhadores, empresários e rentistas; e (ii) a difusão de informação, que põe em evidência as possíveis divergências entre salários e margens de lucro em diferentes segmentos da economia - alimentando, portanto, a primeira motivação.

Como visto, os preços são formados com base nos custos normais e com a adição de um mark-up. Este mark-up é denominado mark-up nominal. O mark-up real é aquele que cobre os custos de reposição, ou seja, aquele que permite que a firma se reproduza. Ele será a remuneração obtida após a produção ser vendida. Assim, o mark-up nominal deve ser tal que os preços futuros garantam o mark-up real desejado. Por isso, será a dinâmica do mark-up nominal que irá ditar a dinâmica inflacionária (Jorge, 2012: 34).

Segundo o modelo de Rowthorn (1980), descrito por Santoro (2015: 26-9), a disputa pela renda ocorre entre capitalistas e trabalhadores, assumindo o pagamento de impostos e a participação do setor externo como exógenos. Essa disputa se dá em cima da determinação dos salários nominais e da taxa de inflação esperada no período seguinte. O poder de barganha dos trabalhadores será decisivo para a determinação do salário nominal, enquanto o poder de repasse de aumentos de custos para preços será determinante para a formação da taxa de inflação do período seguinte. Assumindo que os capitalistas determinam seus preços após o pro- 
cesso de negociação salarial, o repasse para os preços pode não necessariamente ser integral, e neste caso os trabalhadores conseguem alterar a distribuição da renda (Lara, 2008).

Os trabalhadores desejarão repor a inflação passada, de forma que o salário real não se reduza no período seguinte, além de adicionar um componente que corresponda à insatisfação do trabalhador quanto à distribuição de renda vigente na economia. A proporção do quanto o salário irá se elevar efetivamente irá depender do poder de barganha dos trabalhadores. Por outro lado, as firmas irão desejar uma determinada taxa de retorno real, que, como vimos, depende de sua estratégia de crescimento. Para alcançarem seus objetivos, as firmas elevam seus preços sempre que o salário real corrente superar o salário real desejado.

Segundo Lara (2008: 91-2), se há um desejo dos trabalhadores em aumentar seu salário acima da inflação e as firmas não conseguem repassar integralmente o aumento nos seus custos, isto significa que haverá um aumento de salário real. Contudo, se, em um segundo momento, os trabalhadores deixam de exigir um aumento dos salários acima da inflação, os capitalistas continuarão com a capacidade de promover aumentos de preços não previstos e o farão até que o salário real retorne ao salário real desejado pela firma. Se nos períodos subsequentes os trabalhadores continuarem demandando um aumento do salário nominal acima da inflação, e os capitalistas não conseguirem recompor sua margem de lucro de forma integral no período seguinte, isto implicará um aumento real dos salários. Assim, os trabalhadores só irão conseguir alcançar um aumento no salário real de forma persistente caso haja uma taxa de crescimento do salário nominal permanentemente acima da inflação.

Esse conflito entre salários e lucros pode ser arrefecido ou acirrado por fatores exógenos à dinâmica descrita acima. $\mathrm{O}$ aumento da produtividade consegue reduzir o conflito. Isso ocorre uma vez que em um ambiente com crescimento da produtividade ganhos reais de salário são possíveis sem que isso pressione, necessariamente, a margem de lucro real das empresas. Desta forma, "o crescimento elevado não é apenas compativel com a estabilidade de preços, mas uma condição necessária para ele" (Bastos, 2010: 18).

Por outro lado, o conflito será acirrado quando há aumento dos custos intermediários. Um aumento de custos, quando incorporado ao custo "normal”, levará a uma pressão sobre a margem de lucro e, à medida que a firma consegue repassar parte deste para os preços, leva a uma pressão sobre os salários reais. Com isso, aumenta o hiato de aspiração dos trabalhadores que faz com que estes demandem aumentos maiores no salário nominal. Se os trabalhadores têm sucesso em conseguir uma parcela deste aumento, isto ocasiona novamente um aumento dos custos que será em parte repassado para preços. Instaura-se assim um processo inflacionário na economia. A participação dos salários na renda agregada irá depender do poder de barganha tanto dos trabalhadores quanto do poder de repasse de custos para preços dos capitalistas (cf. Santoro, 2015: 28-9).

Até aqui tratamos trabalhadores e capitalistas como grupos homogêneos. Contudo, não é isso que ocorre. Segundo Lavoie (2014: 545), motivado pelo sentimen- 
to de justiça, cada grupo de trabalhadores deseja em suas negociações salariais que a ordem na hierarquia social seja mantida. Isto é, os trabalhadores querem garantir que eles não tenham perda relativa de salários.

Assim, aumentos salariais concedidos para um determinado setor são transmitidos para mercados com diferentes situações econômicas através da difusão da informação, muitas vezes viesada. Se há um aumento da produtividade em um determinado setor, os trabalhadores daquele setor irão desejar um aumento salarial nominal maior. Da mesma forma, os empresários deste setor estarão mais suscetíveis a conceder tais aumentos. Os trabalhadores dos demais setores, contudo, desejando manter sua posição na hierarquia social, e por isso, não desejando ter perdas de salário relativo, irão barganhar um aumento de salário nominal na mesma magnitude. ${ }^{5}$ Uma disputa entre setores acirra o conflito distributivo interno de cada setor, entre trabalhadores e empresários.

Podemos pensar de forma semelhante ao considerarmos as diferentes capacidades que as firmas têm em repassar os custos aos preços nos distintos setores. As diferentes estruturas de mercado e a forma de competição de cada setor determinarão o poder de repasse de aumentos nos custos para preços.

Essa diferença no poder do repasse irá se expressar na variação do mark-up real. Partindo de uma situação em que a firma opera com seu nível de mark-up desejado, aumentos de custos pressionarão seu mark-up real. Caso ela consiga repassar este aumento integralmente para os preços seu mark-up permanecerá o mesmo, deixando sua margem de lucro inalterada; caso a empresa não consiga repassar integralmente o aumento de custos, haverá uma queda de seu mark-up e, consequentemente, de sua margem de lucro. Um aumento de custos, portanto, poderá pressionar os diferentes mark-ups e as margens de lucro das firmas de modo a reforçar o conflito distributivo também em nível intersetorial.

A heterogeneidade dos setores em termos de poder de repasse dos custos ao preço desencadeia um conflito distributivo entre os capitalistas dos diversos setores tentando reaver suas margens. Posteriormente, esse conflito se desdobrará para um conflito entre os capitalistas e trabalhadores do setor com menor poder de repasse. Fazendo, assim, com que os trabalhadores deste último setor sofram perdas em relação aos demais trabalhadores.

Além disso, com diferentes estruturas produtivas as variações de custo terão impactos diferentes nos setores. Dependendo de qual setor é mais suscetível a tal choque este será mais facilmente repassado para preços ou não, impactando assim o conflito distributivo e, consequentemente, a inflação.

A partir deste quadro analítico, observamos que as diferenças setoriais são

\footnotetext{
${ }^{5}$ Se considerarmos que há um limite do quanto de informação conseguimos processar, quando ocorre um processo de negociação salarial apenas a taxa salarial de poucos setores de ocupação será levada em consideração. Geralmente o setor escolhido será aquele que foi mais divulgado pela mídia, que normalmente é a melhor barganha salarial conquistada pelos trabalhadores, e aquele setor que é chave na economia. No Brasil, um importante fator que baliza as barganhas salariais é a variação no salário mínimo.
} 
importantes para a dinâmica da inflação. Mais que isso, a inflação se mostra como um fenômeno complexo, uma vez que diferentes choques irão impactar de formas distintas os setores. Tendo estruturas produtivas diferentes o repasse dos choques para preços não será igual para todas as variações de custo. Cada choque terá um impacto diferente na economia dependendo dos setores mais suscetíveis às suas influências. Assim, avaliar os choques presentes na economia e quais setores estão sendo afetados se torna relevante para o controle inflacionário.

\section{A IMPORTÂNCIA DOS CUSTOS NA DETERMINAÇÃO DA INFLAÇÃO BRASILEIRA NOS ANOS 2000}

São escassos no Brasil estudos que busquem entender o comportamento das firmas na determinação dos preços. Recentemente, contudo, o estudo de Correa, Petrassi e Santos (2016), do Banco Central do Brasil, com base em entrevistas realizadas junto a 7.002 firmas entre julho de 2011 e abril de 2012, presentes em três setores da economia (industrial, serviços e varejista), buscou cobrir esta lacuna. ${ }^{6}$ O estudo se propôs a descrever como as firmas se comportam para determinar seus preços.

O estudo apontou que, segundo as firmas entrevistadas, a competição predominante é a monopolística. A regra de precificação se dá sobre a adição de um mark-up sobre os custos. No setor industrial, que é de especial interesse no nosso estudo, esta regra é utilizada por $52,6 \%$ das firmas que responderam ao questionário. Além disso, neste setor, os principias determinantes dos preços por ordem decrescente de importância são os custos dos bens intermediários, a taxa de câmbio e, em terceiro, a inflação passada. Sobre o impacto da demanda sobre os preços, foi perguntado primeiro se diante de uma variação de demanda as empresas consideram aumentar o tempo de entrega antes de alterar o preço, onde $54 \%$ das firmas de todos os setores responderam que isto era realizado. Ainda foi perguntado se antes de alterar o preço as firmas consideram ajustar os estoques, onde $75 \%$ responderam que elas acomodam variações na demanda com o nível de estoques.

Os resultados encontrados com as entrevistas corroboram a teoria de formação de preços pós-keynesiana que aponta a regra de mark-up como a única forma de precificação das empresas. Ademais, a relevância dos custos intermediários é destacada como principal fator de reajuste de preços e, por fim, as variações na demanda são acomodadas com variações na produção.

Estudos sobre a dinâmica inflacionária no Brasil na visão cost-push inflation são mais frequentes. Em geral investigam se a inflação que predomina na economia será advinda da demanda ou do custo, e também analisam o componente inercial desta. Podemos sintetizar os principais resultados encontrados como: (i) a ambi-

\footnotetext{
${ }^{6}$ Uma investigação abrangente sobre precificação via mark-up com base nos Censos Industriais de 1960 e 1970 encontra-se em Considera (1981).
} 
guidade em relação à demanda; (ii) a grande importância da taxa de câmbio e do preço das commodities para a determinação da inflação; e (iii) a baixa relevância da inflação salarial.

Analisando primeiro as pressões de demanda, Summa (2011) aponta que esta variável não é consenso nas pesquisas para a determinação da inflação. Analisando trabalhos que estimam a curva de Phillips para o Brasil, principalmente após o RMI, com metodologias e paradigmas diferentes, o autor encontra resultados em que a demanda é significativa com o sinal esperado, significativa com o sinal contrário ou não significativa. A variável da demanda foi medida pelo produto efetivo, pela taxa de desemprego ou pelo nível de capacidade ociosa.

Summa e Macrini (2014) estimam os determinantes da inflação brasileira pelo método de redes neurais. Este método capta, além das relações lineares, possíveis relações não lineares existentes entre as variáveis. Eles encontram que quando as pressões de demanda são medidas pelo hiato do produto medido pelo filtro HP, a relação desta variável com a inflação é não linear e cíclica. Assim, hiatos do produto mais altos podem gerar inflação mais alta em determinados períodos e em outros levar à inflação mais baixa. Segundo eles, o recorte amostral faria a diferença para a estimativa, e desta forma a relação aparece em diferentes trabalhos como relações positivas, negativas ou sem relações.

Passando para o setor externo, temos que a relevância da inflação importada, representada pela taxa de câmbio e preço das commodities, é encontrada em todos os trabalhos estudados (Summa e Braga, 2014; Braga, 2011; Summa, 2011; Summa e Macrini, 2014; Santoro, 2015; Modenesi e Araújo, 2011). Summa (2011) mostra que diversos trabalhos encontram forte influência da taxa de câmbio na inflação, indicando que esta variável parece exercer uma pressão inflacionária constante. Modenesi e Araújo (2011), através de um modelo VAR, encontram que o repasse cambial para preços é elevado e persistente, adicionalmente, o efeito acelerador da inflação causado por desvalorizações cambiais demoram a se dissipar. O que demonstra que este tipo de choque inflacionário, que também tem sua influência nos custos, deve se configurar como importante pressão inflacionária. ${ }^{7}$

O impacto da variação salarial na inflação se mostrou relevante apenas em alguns trabalhos, e com impacto reduzido. Braga (2011), ao fazer uma análise desagregada do IPCA entre preços monitorados, setor de serviços, setor industrial e setor varejista, encontra que a variação salarial é relevante para explicar a inflação, principalmente no setor de serviços.

O impacto da inflação inercial também é considerado na maioria dos trabalhos sobre inflação brasileira após RMI. Os resultados encontrados corroboram a ideia de que a inércia inflacionária é parcial, não tendo justificativa para uma curva de Phillips aceleracionista, como supõe a teoria convencional (Summa, 2011). Summa

\footnotetext{
${ }^{7}$ Ver Barbosa (2015), que argumenta que o sucesso do RMI no Brasil está associado a episódios de apreciação cambial, que tende a baratear o custo dos insumos e, portanto, a arrefecer a pressão inflacionária.
} 
e Braga (2014), ao estudarem o IPCA de forma desagregada, encontram que o setor de serviços seria o maior responsável pela inércia inflacionária. Eles argumentam que isto se daria, pois este setor é basicamente composto por não comercializáveis, com baixo crescimento da produtividade e salários vinculados ao salário mínimo.

Jorge (2012) realiza um estudo econométrico sobre os determinantes da inflação de 17 setores da economia brasileira para o período de 1996 a 2011. A autora estima uma curva de Phillips modificada pela metodologia ADL, onde a variável independente é a taxa de inflação medida pelo Índice de Preço por Atacado (IPA) e utiliza como variáveis explicativas a taxa de inflação defasada, o hiato do produto (medido pela utilização da capacidade instalada industrial), a taxa de juros, a variação da taxa de câmbio nominal e inflação dos produtos transacionados no exterior. Os resultados encontrados apontam que a principal variável explicativa foi a inflação importada. Essa variável foi significativa em todos os setores e com alta significância na maioria deles. A taxa de juros também se apresentou significativa em 6 dos 17 setores. Por outro lado, o indicador das pressões de demanda se mostrou pouco relevante no longo prazo. Esse indicador foi significativo em apenas dois setores, o que levou a autora a concluir que não há uma relação forte entre demanda e inflação quando medida pelo IPA nos setores industriais analisados. Quando analisada esta relação no curto prazo, ela se mostrou significativa em seis setores. Assim, o trabalho tem como prognóstico que a inflação industrial brasileira no período estudado é determinada essencialmente por pressões de custo, principalmente ligadas às condições externas.

Por fim, Câmara e Feijó (2016) avaliam a importância relativa dos custos sobre o índice de preço ao produtor da indústria (IPP) de 2010 a 2015. Concluem que as desvalorizações do câmbio explicaram mais de $60 \%$ da variação do preço industrial no período. O exercício econométrico também mostrou que em frente a um aumento da demanda, mesmo com queda no custo unitário do trabalho, as firmas aumentaram sua margem de lucro.

\section{ESTUDO ECONOMÉTRICO}

Esta seção apresenta o estudo econométrico sobre a dinâmica inflacionária de 21 setores industriais no Brasil, no período após a adoção do Regime de Metas de Inflação (RMI), compreendido entre 1999 e 2014.

\section{Modelo Econométrico e Base de Dados}

Com base na análise teórica e na revisão da literatura realizada para o Brasil construímos nossa estratégia empírica. Identificamos três choques importantes que são capazes de afetar a dinâmica inflacionária: (i) choques de custos - salários e insumos; (ii) choques de demanda e (iii) inflação inercial.

Para identificar o efeito de cada um destes choques sobre a dinâmica inflacionária especificamos a equação 1 . 


$$
\pi_{i, t}=\alpha+\beta_{1} \text { Custo }_{i, t}+\beta_{2} \text { Demanda }_{i, t}+\beta_{4} \pi_{i, t-1}+\varepsilon_{i, t} i=1, \ldots, 21 ; t=1999.1, \ldots, 2014.2
$$

Onde: $\pi$ é a inflação, $i$ representa os setores, $t$ representa os meses do período de 1999 a 2014.

Para avaliar a dinâmica inflacionária, optou-se pela metodologia de dados em painel. Esta metodologia se justifica devido à importância da desagregação setorial, que permite considerar a heterogeneidade entre setores. Como proposto pela teoria pós-keynesiana de formação de preços, os setores irão precificar de modo diferente, pelas características históricas e particulares de cada um, o que irá impactar de diferentes modos a inflação agregada.

Os dados utilizados são mensais e a amostra cobre o período de janeiro de 1999 a fevereiro de 2014. O corte temporal foi delimitado a partir da instauração do RMI no Brasil, e vai até fevereiro de 2014 devido à disponibilidade dos dados. Para uniformizar o estudo foi calculada a taxa de variação em 12 meses das variáveis abaixo.

Para os dados de inflação foi utilizada a série de Índice de Preço por Atacado - Oferta Global (IPA-OG) produzido pela Fundação Getúlio Vargas (FGV). Este índice, segundo sua metodologia, registra as variações de preços dos produtos agropecuários e industriais nos mercados intermediários, isto é, antes do bem ser vendido como produto final. Assim ele é um índice de preços do produto no nível do produtor.

Para medirmos os choques advindos pelo lado da demanda, usamos uma medida de ciclo econômico, que corresponde ao hiato do produto. Este é calculado a partir dos dados da Pesquisa Industrial Mensal de Produção Física divulgada pelo Instituto Brasileiro de Geografia e Estatística (PIM-PF/IBGE) que acompanha a evolução do produto real da indústria no curto prazo.

$\mathrm{O}$ hiato do produto do setor $i$ no período $t, \mathrm{H}_{i, t}$, foi calculado a partir da diferença entre o produto do setor $i$ no período $t, \mathrm{Y}_{i, t}$, e o produto de longo prazo do setor $i$ no período $t, \mathrm{Y}_{i, t}^{*}$. Este último é calculado através dos próprios dados da série, para cada setor, pelo filtro Hodrick-Prescott.

Para medir os choques advindos pelo lado dos custos de insumos utilizou-se o índice de custos $\left(\mathrm{C}_{i, t}\right)$, da atividade $i$ no período $t$, construído por Pimentel et al. (2016) a partir da tabela de consumo intermediário das Contas Nacionais de 2005, fornecida pelo Sistema de Contas Nacionais do Instituto Brasileiro de Geografia e Estatística (SCN/IBGE). Ele corresponde à média dos preços no período $t$ dos bens $j, \mathrm{P}_{j, t}$, utilizados no processo de produção da atividade $i$, ponderados por $\mathrm{s}_{i, j}$, que representa o peso que a atividade $j$ teve na produção da atividade $i$ de acordo com a tabela de consumo intermediário.

$$
C_{i, t}=\sum s_{i, j} \times P_{j, t}
$$

Para a estimativa do impacto dos salários, utilizamos os indicadores da Pesquisa Industrial Mensal de Emprego e Salários (PIMES) produzida pelo IBGE re- 
ferente ao Valor da Folha de Pagamento por trabalhador. Essa série apresenta dois problemas. Primeiro, a amostra não cobre todo o período de nossa análise. Trabalhando com os dados em variação em 12 meses, a série tem início em novembro de 2001. Um segundo problema é que a série capta o valor da folha de pagamentos, o que inclui além do salário contratado, acréscimos feitos a esse, como décimo terceiro salário, horas extras, gratificações e outros rendimentos extras.

Considerando as variáveis proxies para os choques listados acima, a especificação que usamos é dada pela equação (3).

$$
\pi_{i, t}=\alpha+\beta_{1} \text { custos }_{i, t}+\beta_{2} \text { salarios }_{i, t}+\beta_{3} \text { hiato }_{i, t}+\beta_{4} \text { ipa }_{i, t-1}+\varepsilon_{i . t}
$$

\section{Metodologia Econométrica}

Para realizar a estimação do modelo foi utilizada a metodologia de dados de painel que consiste em agrupar dados de diferentes unidades observacionais ao longo do tempo. Como ressaltado anteriormente este método foi escolhido pois permite controlar a heterogeneidade individual de cada setor, o que, em nossa análise, é de extrema importância. Desta forma, levamos em consideração a heterogeneidade setorial para realizar nossa estimação, contudo não foi possível estimar o quanto as diferenças setoriais impactam a variação dos preços. ${ }^{8}$

Para incluir a informação de salário em nosso modelo, cuja série é menor, optamos por estimar dois modelos.

A Especificação 1 equivale à equação (3), onde os custos com salários são considerados. Sua amostra então foi reduzida e compreende de novembro de 2001 a fevereiro de 2014. É a especificação do nosso modelo mais fidedigna à teoria elaborada, uma vez que inclui todos os choques capazes de afetar a inflação.

Já a Especificação 2 corresponde a equação (4) sem levar em consideração os salários. Sua amostra cobre todo o período de análise que vai de janeiro de 1999 a fevereiro de 2014.

$$
\pi_{i, t}=\alpha+\beta_{1} \text { custos }_{i, t}+\beta_{2} \text { hiato }_{i, t}+\beta_{3} \text { ipa }_{i, t-1}+\varepsilon_{i, t}
$$

O modelo em painel da Especificação 1 apresenta 21 setores industriais correspondendo a 148 observações ao longo do tempo (2001.11-2014.2). Para a Especificação 2 temos os mesmos 21 setores e 182 observações (1999.1-2014.2). Desta forma, ambas as especificações tratam de um painel longo, onde $i<t$, e $t \rightarrow \infty$.

Devido à presença da variável dependente defasada em nossa especificação, com fins de avaliar a inflação inercial, estamos tratando de um modelo dinâmico. Por isso, optou-se por utilizar o método de momentos generalizados (GMM) de dois passos desenvolvido por Arellano e Bond (1991). Este método, segundo Baltagi (2005: 136-

\footnotetext{
${ }^{8}$ Os testes de raiz-unitária das variáveis, bem como os testes de autocorrelação dos resíduos e super-identificação das restrições foram realizados e se encontram disponíveis por contato com os autores.
} 
142), utiliza variáveis instrumentais para obter a variável defasada e assim realizar a estimação. No caso do GMM, o instrumento utilizado é a própria variável defasada em mais períodos, o que retira a autocorrelação entre o regressor e os resíduos.

Com base na teoria desenvolvida, consideramos o hiato da produção como sendo exógeno em relação à variação no nível de preços, uma vez que o nível de produção das empresas não é definido com base nos preços. Os custos e os salários, por sua vez, foram considerados endógenos em relação à variação do nível de preços, isto é, a variação em 12 meses destas variáveis é correlacionada contemporaneamente e futuramente aos resíduos.

O número de defasagens utilizadas no modelo como regressores foi determinado a partir da teoria. Assumindo que a maior parte das empresas modifica seus preços semestralmente ou anualmente, consideramos, então, que a inflação dos 12 meses anteriores seria relevante para explicar a variação dos preços em $t$. Assim, utilizou-se uma defasagem como regressor para cada variável endógena, isto é, $\mathrm{IPA}_{(\mathrm{t}-1)}$, Custos $_{(\mathrm{t}-1)}$ e Salários $(\mathrm{t}-1)$.

Como colocado por Cameron e Trivedi (2009: 291), quando $t$ é grande o método gera muitos instrumentos, o que pode levar a performances ruins dos resultados assintóticos. Assim, limitamos o número de instrumentos a 2 lags. Então, por exemplo, quando $t=9$, os instrumentos para o $\mathrm{IPA}_{\mathrm{i}, 8}$ serão $\operatorname{IPA}_{\mathrm{i}, 7}$ e IPA $\mathrm{IA}_{\mathrm{i}, 6}$.

Baltagi (2005: 136) e Roodman (2006: 42) colocam que com painéis longos, onde $t \rightarrow \infty$, o estimador de efeito fixo por Mínimos Quadrados Ordinários (MQO) se torna consistente mesmo em modelos dinâmicos. Este método consiste em retirar do componente de erro aqueles parâmetros que são características intrínsecas daquele setor e que não variam ao longo do tempo. Isso leva a que os efeitos das variáveis omitidas que se alteram entre indivíduos, mas não ao longo do tempo, sejam controlados. Assim, este método será utilizado adicionalmente a fim de compararmos com o modelo estimado por GMM e dar maior robustez aos resultados.

\section{Modelagem e Resultados}

A Tabela 1 apresenta os resultados encontrados sob os dois métodos utilizados. ${ }^{9}$

Primeiramente foi realizado o método GMM para Especificação 1, onde é incluída a série de salários. A variação de custos contemporânea é a variável mais relevante para explicar a mudança no nível dos preços. O sinal do parâmetro indica que os custos impactam positivamente a variação dos preços, como esperado. As demais variáveis não podem ser consideradas estatisticamente significativas no nível de $1 \%$ ou $5 \% .^{10}$

\footnotetext{
${ }^{9}$ Devido à presença de raiz unitária nas variáveis foi utilizada a primeira diferença destas para a análise.

${ }^{10}$ Somente no nível de $10 \%$ de significância o hiato do produto pode ser considerado significativo, porém apresenta sinal inverso ao esperado teoricamente: um aumento no hiato do produto reduziria a inflação, ao invés de aumentá-la.
} 
Tabela 1: Resumo dos resultados do estudo econométrico

\begin{tabular}{|c|c|c|c|c|}
\hline \multirow[b]{2}{*}{ VARIABLES } & \multicolumn{2}{|c|}{ Especificação 1} & \multicolumn{2}{|c|}{ Especificação 2} \\
\hline & GMM & $\begin{array}{c}\text { MQO } \\
\text { Efeito fixo }\end{array}$ & GMM & $\begin{array}{c}\text { MQO } \\
\text { Efeito fixo }\end{array}$ \\
\hline \multirow[t]{2}{*}{$\operatorname{dipa}(t-1)$} & 0.186 & 0.0976 & 0.108 & $0.0955^{*}$ \\
\hline & $(0.217)$ & $(0.0603)$ & $(0.0873)$ & (0.0494) \\
\hline \multirow[t]{2}{*}{ dcustos } & $1.259 * * *$ & $1.023^{* * *}$ & $1.127^{* * *}$ & $1.001 * * *$ \\
\hline & (0.163) & $(0.110)$ & (0.0658) & $(0.0871)$ \\
\hline \multirow[t]{2}{*}{ dcustos(t-1) } & -0.452 & & $-0.197^{*}$ & \\
\hline & $(0.404)$ & & (0.105) & \\
\hline \multirow[t]{2}{*}{ dsalarios } & -0.00573 & -0.00226 & & \\
\hline & $(0.00841)$ & $(0.00497)$ & & \\
\hline \multirow[t]{2}{*}{ dsalarios(t-1) } & -0.000964 & & & \\
\hline & $(0.00784)$ & & & \\
\hline \multirow[t]{2}{*}{ Hiato } & $-0.0164^{*}$ & $-0.0115^{* *}$ & -0.00584 & -0.00677 \\
\hline & $(0.00921)$ & $(0.00545)$ & (0.00429) & $(0.00455)$ \\
\hline \multirow[t]{2}{*}{ Constant } & $9.76 e-05$ & 0.000131 & $0.000161 *$ & $7.66 e-05$ \\
\hline & $(0.000123)$ & $(0.000912)$ & (8.51e-05) & (0.000755) \\
\hline Observations & 3,024 & 3,066 & 3,759 & 3,780 \\
\hline Number of SETORES & 21 & 21 & 21 & 21 \\
\hline \multicolumn{5}{|c|}{ Robust standard errors in parentheses } \\
\hline
\end{tabular}

Para a Especificação 2 obtivemos resultados similares quanto à significância e importância das variáveis. A variação contemporânea dos custos é a principal variável explicativa da mudança nos preços. A variação dos custos defasada em um período apresenta, porém, sinal contrário ao esperado. A magnitude dos efeitos dos custos, contudo, é substancialmente positiva se considerarmos a agregação dos valores dos parâmetros estimados. Nesta especificação, o hiato do produto não se mostrou significativo estatisticamente aos níveis convencionais.

Os dois modelos GMM não apresentam autocorrelação dos resíduos para ordens superiores à primeira e com a superidentificação dos parâmetros válida.

Sob a metodologia de MQO com efeito fixo para a Especificação 1 encontramos resultados levemente diferentes do modelo GMM. A principal variável para explicar a variação nos preços continua sendo a variação dos custos. Nesta especificação, contudo, o hiato do produto se mostrou significativo e com uma correlação negativa com a variação dos preços, o que não é esperado pela teoria. $\mathrm{O} \mathrm{R}^{2}$ 
do modelo não foi muito elevado, da ordem de $55 \%$, indicando baixo poder explicativo do modelo.

Para a Especificação 2 a variável mais significativa para explicar a variação do nível de preços continua sendo a variação do índice de custos, seguida pela variação dos preços defasada. A variação do hiato deixa de ser significativa sobre esta abordagem. $\mathrm{O} \mathrm{R}^{2}$ do modelo também permaneceu de $55 \%$, mostrando o baixo poder explicativo do modelo.

O estudo econométrico mostra que o principal determinante da dinâmica inflacionária foi a variação do índice de custos intermediários. O impacto da variação dos custos sobre a variação dos preços foi estatisticamente significativa em todas as especificações. Mais que isso, em todas elas se mostrou como a principal variável na determinação da inflação. Isto indica, portanto, robustez quanto ao impacto dos custos sobre a dinâmica inflacionária industrial, sendo aquele correlacionado positivamente com os preços. Tal resultado é consistente com a linha teórica desenvolvida, que atribui aos choques de custo o protagonismo da dinâmica inflacionária. A variação do hiato do produto se mostrou significativa apenas nas estimações da Especificação 1 e com sinal inverso do esperado. Ao passo que a variação dos preços defasada foi significativa na estimação da Especificação 2 sob a metodologia de MQO com efeito fixo. A variação dos salários não foi significativa em nenhuma das especificações.

Como discutido, esperávamos que a variação do hiato do produto, que estaria medindo os choques advindos pelo lado da demanda, não fosse relevante para explicar a dinâmica inflacionária. Desta forma, assumindo que os preços são formados a partir de uma regra de mark-up sobre os custos normais, pela teoria do conflito distributivo, os choques de demanda poderiam ter apenas um impacto indireto na dinâmica inflacionária ao dar maior poder de barganha aos trabalhadores e maior poder de repasse dos custos para os preços aos empresários.

Assim, nossos resultados mostram que a dinâmica da inflação industrial no período analisado não pode ser explicada por pressões advindas da demanda. A significância estatística da variável em apenas um modelo e no nível de $10 \%$, e com uma correlação negativa, sugere que há uma relação muito tênue entre pressão de demanda e dinâmica inflacionária, favorecendo a hipótese de que o seu impacto é muito indireto. Conclui-se que o diagnóstico de inflação de demanda pela teoria monetária do RMI perde força pela análise empírica apresentada, uma vez que os custos se revelam preponderantes e os efeitos de choques de demanda, muito tênues.

A variação salarial era esperada, significativa em nosso modelo, uma vez que se constitui em um importante custo para as empresas e cresceu no período estudado. Entretanto, outros trabalhos que buscaram entender a dinâmica inflacionária recentemente chegaram a resultados semelhantes. Summa (2014), ao estudar especificamente a relação entre valorização do salário mínimo e inflação, sugere que o impacto dos salários sobre os preços foi baixo, principalmente no período de 2000 a 2003. Além disso, o autor aponta que o impacto do custo salarial será menor sobre os bens industriais quando comparado a demais setores, como serviços livres. Jorge (2012) encontra resultado semelhante em sua análise da dinâmica inflacionária em nível setorial. Segundo seus resultados apenas 3 setores, de 17 estudados pela autora, apresentaram pressões salariais sobre a inflação. 
A variação de preços defasada em um período se mostrou significativa no nível de $10 \%$ em apenas uma das estimações para explicar a variação de preços, não sendo, portanto, um resultado robusto. Seu coeficiente, apesar de ter o sinal esperado, tem uma baixa magnitude. Este resultado diverge de trabalhos anteriores, que encontraram uma elevada correlação entre a inflação corrente e a passada. A inflação inercial brasileira é um fator relevante desde a década de 1980. O trabalho de Braga (2011) aponta que o setor de serviços é o principal responsável pela indexação da economia. Uma vez que estamos lidando neste trabalho apenas com os setores industriais, o impacto da inércia pode estar minimizado. Outra possibilidade, que pode acentuar essa redução, é que parte do efeito esperado da inércia pode estar sendo captada pelo próprio índice de custos, que carrega em sua variação importante componente histórico.

Por fim, vale observar que o consumo intermediário das firmas está permeado por insumos importados. Em 2005, ${ }^{11}$ o coeficiente de penetração de importações da indústria de transformação ${ }^{12}$ era de $11,9 \%$. Assim, percebemos que quase $12 \%$ do impacto da variação dos custos pode ser advindo de variações nos preços internacionais ou da taxa de câmbio. Jorge (2012) encontra que o principal fator explicativo na determinação inflacionária dos 17 setores estudados está no câmbio. Desta forma, entendemos que parte desta variação dos custos, captada pelo nosso modelo, pode estar refletindo alterações cambiais. Contudo, não conseguimos diferenciar a variação dos insumos nacionais da dos insumos internacionais.

\section{CONCLUSÃO}

O presente trabalho apresentou uma análise empírico-quantitativa sobre os determinantes da inflação industrial brasileira no período de 1999 a 2014. Esta análise teve como referencial teórico a teoria de formação de preços pós-keynesiana e a abordagem do conflito distributivo, sendo a primeira uma discussão de caráter eminentemente microeconômico, ao passo que a segunda explica a dinâmica da inflação no nível macroeconômico, partindo da reação de firmas e trabalhadores no nível microeconômico. Desta forma, buscou-se integrar as duas abordagens de modo a levar em conta como a heterogeneidade setorial afeta o comportamento da inflação no agregado - no caso, a inflação industrial.

A principal conclusão é que os custos intermediários são os principais determinantes da variação dos preços industriais. Esses representam os custos considerados no nível normal de produção e, por isso, não se associam a mudanças na demanda. A heterogeneidade setorial é um importante fator a ser considerado

\footnotetext{
11 Como o índice de custos é construído com base fixa do consumo dos setores no ano de 2005 utilizamos este ano de referência para este fator.

12 Dos 21 setores analisados, 19 pertencem à indústria de transformação. Contudo, quando passamos para os setores de minerais metálicos e minerais não metálicos, o coeficiente de penetração no ano de 2005 é, respectivamente, $29,7 \%$ e $10,1 \%$. O coeficiente de penetração da indústria total é de $13,7 \%$ neste mesmo ano.
} 
neste caso, uma vez que variações de custo não têm o mesmo impacto em cada setor e pelo seu repasse aos preços ser de forma diferenciada.

A inflação inercial se mostrou significativa apenas quando utilizado o método econométrico de MQO com efeito fixo. Esta variável foi relevante em outros trabalhos que estudaram a dinâmica inflacionária. Seu resultado com baixa robustez pode indicar que seu efeito pode estar sendo captado pelo componente histórico do índice de custos.

A demanda agregada teve baixa correlação com a dinâmica inflacionária, sendo significativa apenas em duas das regressões realizadas e com sinal contrário ao esperado. Isto indica uma relação muito tênue entre as variáveis favorecendo a base teórica de que o impacto da demanda sobre a inflação seja apenas indireto.

Por fim, os salários não foram significativos em nenhuma das estimações realizadas. Este foi um resultado inesperado dada a teoria estudada e que houve crescimento do salário real sem que houvesse compensação na produtividade no período. Este resultado pode indicar que dada a concorrência externa os setores industriais tiveram baixa capacidade de repasse deste aumento para preços.

Em meio a este contexto, o aumento de juros como forma de controle inflacionário, como prega o RMI, pode não se mostrar eficaz, uma vez que terá impacto baixo sobre os custos, e por vezes adverso. Este mecanismo terá um impacto sobre os efeitos secundários sendo necessária uma forte contração da demanda para que haja uma redução da inflação razoável, uma vez que a relação entre essas variáveis é tênue e indireta.

Além disso, o aumento da taxa de juros pode ter um impacto adverso sobre os preços. Eles permitem maior repasse para preços das variações positivas dos custos por duas vias. Primeiramente ela representa custo para as firmas endividadas. Assim, um aumento da taxa de juros irá comprimir ainda mais a margem de lucro sendo mais uma fonte de pressão sobre os preços. Por outro lado, a taxa de juros representa o custo de oportunidade entre o custo de aplicação do investimento na esfera produtiva ou na esfera financeira. Elevações na taxa de juros serão percebidas como um aumento do custo de se manter o capital na produção, fazendo com que seja necessário aumentar o mark-up para se equiparar ao rendimento obtido caso o capital estivesse na esfera financeira.

Pelo estudo aqui realizado, o combate à inflação deveria levar em consideração as diferenças setoriais para que um setor menos inflacionário não sofresse o impacto da política antiinflacionária da mesma forma que os setores inflacionários, ou seja, aqueles com maior poder de repasse. A própria diferença setorial leva a que as respostas às políticas sejam diferenciadas. Assim, a contribuição deste trabalho é na direção de apontar para a necessidade de se desenhar uma política monetária mais fina, identificando quais choques estão presentes na economia e a melhor forma de combatê-los. O RMI, ao pregar um único mecanismo quando há variação de preços, desconsidera essas nuances e apresenta baixa eficácia no caso da economia brasileira, sendo necessária forte recessão econômica, como em 2015 e 2016, para que ocorra uma redução significativa da inflação. 


\section{REFERÊNCIAS BIBLIOGRÁFICAS}

BALTAGI, B.H. (2005). Econometric analysis of panel data. England: John Wiley \& Sons Ltd.

BARBOSA, N. (2015). “O desafio macroeconômico de 2015-2018”, Revista de Economia Política, vol. 35 , no. 3, pp. 403-425.

BASTOS, C.P.M. (2010). “Conflito distributivo e inflação”. Textos para Discussão Cepal/Ipea, n 11 .

BASTOS, C.P.M. ; JORGE, C.T. ; BRAGA, J.M. . "Análise desagregada da inflação por setores industriais da economia brasileira entre 1996 e 2011”. Revista de Economia Contemporânea , v. 19, pp. 261-279.

BRAGA, JULIA DE MEDEIROS (2013). "A inflação brasileira na década de 2000 e a importância das políticas não monetárias de controle.” Economia e Sociedade, v. 22, pp. 697-727.

CAMARA, F.; FEIJO, C. (2016). "Industrial pricing in Brazil in the 2010s: The pass-through effect". EconomiA (2016), vol. 18, issue 1, pp. 60-72.

CAMERON, A.C. E TRIVEDI, P.K. (2009). Microeconometrics Using Stata. Texas: Stata Press.

CLARIDA R.; GALÍ J.; GERTLER, M. (1999). "The Science of Monetary Policy: A New Keynesian Perspective". Journal of Economic Literature, Vol. XXXVII, pp. 1661-1707.

CONSIDERA, C M . (1981) "Preços, mark-up e distribuição funcional da renda na indústria de transformação: dinâmica de longo e curto prazo - 1959/1980," Pesquisa e Planejamento Econômico, vol. 11 , no. 3 .

CORREA, A.S.; PETRASSI, M.B.S.; SANTOS, R. (2016). "Price-Setting Behavior in Brazil: survey evidence". Banco Central do Brasil - Working Papers n 422, March.

EICHNER, A. (1976). The Megacorp and Oligopoly, New York, M. E. Sharpe.

FEIJO C. A . (1993). "Decisões empresariais numa economia monetária de produção: notas para uma teoria pos keynesiana da firma”. Revista de Economia Política, vol. 13, no. 1 (49), pp. 82-100.

HALL, R. L.; HITCH. C. J. (1939). Price theory and economic behaviour. Oxford Economic Papers.

JORGE, C.T. (2012). "Análise Desagregada da Inflação por Setores Industriais da Economia Brasileira entre 1996 e 2011”. Dissertação de mestrado apresentada a PPGE/UFRJ.

LARA, F.M. (2008). "Um Estudo sobre Moeda, Juros e Distribuição”. Tese de doutorado apresentada ao PPGE /UFRJ.

LAVOIE, M. (2014). Post-Keynesian Economics: New Foundations. Cheltenham, UK: Edward Elgar.

LEE, F.S. (1999). Post Keynesian Price Theory. New York, USA: Cambridge University Press (Virtual Publishing).

MODENESI, A. M.; ARAÚJO, E. (2011). Custos e Benefícios do Controle Inflacionário no Brasil: Uma Análise Empírica do Mecanismo de Transmissão da Política Monetária Com Base Em Um Modelo Var. Anais do XXXVIII Encontro Nacional de Economia, ANPEC.

MONTANI MARTINS, N.; PIRES-ALVES, C.; MODENESI, A.M.; LEITE, K.V. (2017). "The transmission mechanism of monetary policy: Microeconomic aspects of macroeconomic issues", Journal of Post Keynesian Economics, vol. 40(3), pp 300-326.

PENROSE, E. 1980. The Theory of Growth of the Firm, White Plains, M.E. Sharpe.

PIMENTEL, D.; MODENESI, A. M.; PIRES-ALVES, C. C.; RIBEIRO, E. P. (2016) "Assimetria no repasse de custos a preços: Uma análise para 21 atividades industriais no Brasil de 1996 a 2014". In: IX International Conference of the Brazilian Keynesian Association, 2016, São Paulo.

SANTORO, J.P.C. (2015). “A Inflação Brasileira entre 2000 e 2014: um Enfoque Heterodoxo”. Dissertação de mestrado apresentada a PPGE/UFRJ.

SUMMA, R. (2011). “Uma Avaliação Crítica das Estimativas da Curva de Phillips no Brasil”, Pesquisa \& Debate, SP, volume 22, número 2 (40), pp. 157-183.

SUMMA, R. (2016). "Uma nota sobre a relação entre salário mínimo e inflação no Brasil a partir de um modelo de inflação de custo e conflito distributivo". Economia e Sociedade, vol.25, n.3, pp.733-756.

BRAGA, J.M. E SUMMA, R. (2016). "Estimação de um modelo desagregado de inflação de custo para o Brasil”. Ensaios FEE, v. 37, n. 2, pp. 399-430.

SUMMA, R. E MACRINI, L. (2014). "Os determinantes da inflação brasileira recente: estimações utilizando redes neurais.” Nova Economia, Belo Horizonte, 24 (2), pp. 279-296, maio-agosto. 